\title{
Determinants of Satisfaction with Health Care System
}

\author{
Peter Kotzian*
}

Technical University of Darmstadt, D-64283 Darmstadt, Germany

\begin{abstract}
Political debates on the reform of health systems are stimulated by dissatisfaction of citizens with their health system. To adapt health systems in order to achieve more satisfaction, policy makers must know what citizens expect from it, in particular, what actually determines the citizen's satisfaction.

The paper will analyze the topic of satisfaction with health systems under three aspects: What properties and outputs of the health system are most important for citizens satisfaction? What properties of the individuals and the society affect the individual's satisfaction? Moreover, is there a systematic interaction among individual and societal factors in the sense, that societal features determine what is most relevant for individual satisfaction? In particular, does this interaction operate by the mechanism that overall societal development changes the expectations of citizens regarding the health system?

At the theoretical level, the paper provides an explanation of why in particular wealth and economic development might change the criteria by which citizens evaluate their health system. The paper empirically analyzes the impact of individual-level attitudes and features located at the health system level on an individual's satisfaction with the health system using Eurobarometer survey data. The findings indicate that of the different types of health system output, the restoration of physiological health is no longer crucial for satisfaction. While not irrelevant, this output is taken for granted. Instead, "beyond-health outputs", like responsiveness, are the main determinants of satisfaction in developed countries.
\end{abstract}

Keywords: Satisfaction with health system, multilevel models, health system performance, health system output.

\section{INTRODUCTION}

Health systems are under the pressure to adapt to changing economic and demographic circumstances and have been under this pressure since a long time; cf. Saltman et al. (1998). Political science and health economics are both seen as being in the role of informing health policy makers what to change in order to achieve certain, politically defined targets, in particular to satisfy citizens in their role as patients, payers and voters. As a result, in particular the border between political science and health economics has become fuzzy, leading to a strand of research merging both disciplines.

The pressure to adapt the health system is reflected in at times frantic political efforts of reforming and changing the health system on any scale - from details of remuneration to the very principles on which the health system is based, e.g. like public or private provision of services; cf. OECD (2004a,b) and Oliver \& Mossialos (2005). There are "perennial" issues, such as ensuring sufficient funding, cost control, equity in access, and, more recently, quality assurance. Another question is, whether the health system actually delivers what citizens expect from it, and of course, what this might be. Listening to some health policy makers and in particular citizens, shows that "health" might no longer be the one and only answer. The political impact of the latter question arises from the fact that citizens' expectations and demands are

\footnotetext{
*Address correspondence to this author at the Technical University of Darmstadt, D-64283 Darmstadt, Germany;

E-mail: kotzian@pg.tu-darmstadt.de
}

transmitted by the political process into a health policy, which will in the long run also affect the institutional design of the health system. While health care is but one issue in the electoral arena, and maybe not even the predominant one, political parties also compete by offering different options of how health care shall be organized and how it shall be delivered. If the citizens consistently demand a health system delivering certain outputs, the political process will in the long run create a health system which delivers this very output, whatever it may be. At least, political actors will try to install such a system based on what they perceive the preferences of the citizens to be and their understanding of how the system can be changed in order to satisfy these preferences.

While prima facie, there should not be a divergence between demands and reality, a closer look shows that there is a gap between the discourse (usually focusing on expenditure) and what citizens actually want. Survey-based research on health system output, performance and satisfaction with the health system has come up with a set of seemingly conflicting observations.

First, the overall "biological" health status, in particular the "default health status", in industrialized countries is as high as never before. People are relatively healthy by default. While much or even most of this achievement may be due to improved overall living conditions which prevent the occurrence of illnesses, see Cutler et al. (2006), the health systems in industrialized countries are objectively doing quite well in curing illnesses once they occur and in avoiding the mortality which is amenable to medical intervention, see Nolte \& McKee (2003). There is, objectively, no reason to be dissatisfied with the system because of lacking performance in terms of "producing" health. 
Second, both the political discourse in the domain of health policy and the public debate are focusing on funding issues in a highly narrowed way: in many countries, the level and in particular the dynamics of health expenditure are denounced to be too high, and unsustainable, often without recurring to the issue of what citizens get for their money and whether limiting health expenditure should be an "absolute" political aim; cf. Aaron (2003). Looking at health reforms aiming at cost containment, in particular at the smaller changes which take place within a given institutional setting, they often factually concern the extension of the funding base: introducing or extending co-payments to "core" services or by removing services from the regular catalogue in order to tap private funding as an additional source, cf. Mossialos et al. (2002).

Third, satisfaction with health systems differs substantially among industrialized countries. As for the reasons in these differences, the costs and benefits of the system are seen as relevant, but several authors indicate that citizen's rising and maybe even changing expectations are also sources of differences in levels of satisfaction; cf. Mossialos (1997), Blendon et al. (2001) and Kohl \& Wendt (2004). Just as health care expenditure, satisfaction is a permanent issue in health politics, both at the level of the relationship between patient and the provider of the medical service and at the level of the health system as a whole, cf. Sitzia \& Wood 1997, Jackson et al. (2001), Dusheiko et al. (2004) and Ham (2005).

Health policy makers are seemingly confronted with a dilemma: the health systems objectively do a good job, but citizens are often dissatisfied. Institutional changes and reforms, which often focus on cost control, while leaving the level of biological outputs unchanged, are not increasing the satisfaction with the system; cf. Saltman \& Figueras (1998) and Donelan et al. (1999).

This paper shall investigate the following questions: What determines the satisfaction of citizens with their Health Care Systems, henceforth abbreviated HCS? Is it the system's output, or rather the financial burden it imposes on the citizens? What are citizens demanding and expecting from their HCS? Is this the same in all countries? Do demands and expectations change parallel to the society's socio-economic development? If they do, for what reasons and in what manner do they change?

\section{ANALYTICAL FRAMEWORK}

\section{The Analytical Framework of the Paper is as Follows}

First, there are different kinds of services provided and outputs produced by the HCS. The one kind - health outputs - concerns the restoration of biological health, the other kind, denoted as beyond-health outputs, concerns among other things the process of restoring health, cf. in particular Newhouse (1977) and Mooney (1998). Each of them requires resources, such as funding and manpower, but also a HCS which is at the institutional level designed to allow for the production of these services and outputs. The question is, which output is most important for citizens' satisfaction?

Second, there is evidence that the importance of different HCS outputs for individual satisfaction differs among countries. Indeed, two HCS which are very similar in all crucial regards, such as performance, the mix of outputs, and costs, may be evaluated very differently by the "clients". What is satisfying for citizens in one country, may be dissatisfying for citizens on another. I will argue that this is due to different preferences and expectations held by the citizens. The conceptual question then is, why one might expect citizens' preferences regarding health care and the mix of outputs to be conditional and on what? The empirical question is, Is there actually a change in citizens' expectations and preferences for different kinds of outputs?

The paper will briefly elaborate on the two basic types of outputs a HCS delivers and then propose an explanation, when and why citizen's satisfaction with the HCS is determined by the one rather than the other output, depending on the level of socio-economic development a society has reached. The proposed explanation will be tested using a multilevel regression analysis combing survey data with information on the levels of each of the different outputs produced by the HCS. The results indicate that indeed the citizen's expectations change in accordance with the explanation proposed: the beyond-health outputs are much more important for satisfaction than the health outputs.

The concluding section discusses implications for health policy, basically arguing that beyond the rhetoric, often joined by the citizens themselves, citizens factually demand an additional output, viz. beyond-health output. Interestingly, in the public and the political discourse, this output is often not addressed at all. Given its relevance, the output should be explicitly discussed and be included in the "value for money" calculation on which the judgment that a certain HCS is "too expensive" is based.

\section{TYPES OF HEALTH SYSTEM OUTPUTS AND CITI- ZENS' PREFERENCES FOR THEM}

Health is seen as one of the most basic human needs, literally the necessary condition for virtually everything else in life. In this view, health services are provided for a clearly defined end, viz. the restoration of health. Consequentially, one could argue that only services which clearly aim at improving biological health are demanded from the HCS. Further, that these services are only demanded by ill people and only for as long as they are ill. Ceteris paribus, one would also expect that the services provided are evaluated only with respect to the outcome, i.e. the restoration of biological health. If this were true the health levels achieved by the HCS should be the criterion which is most important for citizen's satisfaction with the HCS. If the HCS is able to create a high life expectancy, able to avoid mortality by curing illnesses, the HCS is doing its job and citizens will be satisfied. Contrary, if the medical care provided is insufficient in quantity or quality, if people suffer from illnesses which go untreated for whatever reason, the HCS is not doing its job and citizens are rightly dissatisfied.

If all this were true, the assignment for the political system would be straightforward: Design a HCS which guarantees quality care (e.g. by high standards for medical education), access to medical care (also for preventive measures) and moreover give the HCS the funding necessary for operating, i.e. to cure all illnesses which are occurring in a timely fashion. 
Contrary to this straightforward and arguably simplistic view, a provocative article by Joseph P. Newhouse, after comparing health expenditure and health status in industrialized countries, stated that the production of biological health is not what the observable increase in health care expenditure (henceforth HCE) is spend for. Rather, the additional spending is spend to 'buy more caring, but little additional curing'; (Newhouse 1977, 122). In Newhouse' view HCS - at least in industrialized countries - are no longer restricted to the restoration of biological health, but are also producing 'improvements in so-called subjective components of health. (...) alleviate symptoms (for example, pain, itching), relieve anxiety, and provide prognostic information '; (Newhouse 1977, 122). The argument of the two different outputs of the HCS was taken up and elaborated, for instance in the distinction between health-outputs and beyond-health outputs proposed by Mooney (1998).

An example of "caring" is helping people to cope with an illness by way of psychological support. A more clear cut example of beyond-health-output is the way health is produced by the HCS. Independent from the outcome in biological terms, the way a medical treatment is delivered also creates benefits, process utility, which is demanded by the patients. For instance, patients might be willing to pay for the usage of less invasive surgery methods which are equally effective but more expensive, cf. Donaldson \& Shackley (1997, 700); see also Olsen \& Smith (2001) on patients' willingness to pay for process utility. Aspects like accommodation standards in hospitals also fall into this category. Another typical example of beyond-health-output is the responsiveness of the HCS to the patient's preferences, its "customer orientation". Responsiveness expresses itself in particular by offering the patient a role in the medical decision making: enabling the patient to take a role by providing the information required to understand the options and to make a decision, and paying attention to the patient's dignity and preferences; see Valentine et al. (2000) and WHO (2000, pp147). In particular the responsiveness of the HCS as defined and measured by the WHO in its 2000 World Health Report encompasses aspects which relate to how health is restored, e.g. customer attention, being attentive and being respectful to the patient.

In a crude but illustrative way, "curing" can be defined as follows: health can be restored by medical personnel treating the patient just like an object in need of repair. The medical staff identifies the problem and "repairs" it to the extent of the medical and technological possibilities. There is usually no role for the patient, who is neither involved in the decision making nor is enlightened about what is done and why. The physician evaluates the options and decides what is best. At most, the patient is confronted with a take it or leave it decision. While this might not affect the biological outcome of the treatment, people might be nevertheless be willing to pay for being treated in a polite and respectful way, and in particular to be involved rather than subjected to the decision making by the medical staff. All these outputs, e.g. involving the patient, require resources, driving up HCE. While theses outputs accompany those measures and interventions by which the biological health is restored, they are not actually contributing to restoring health, they have no return in terms of "biological health".

\section{Explaining Changing Preferences for Health Care Out- puts}

Contrary to the argument of Grossman's (1972) model of the demand for health care (who predicts that more of the same thing, i.e. curing, is consumed as people get richer), Newhouse argues explicitly that a different type of services is demanded from the HCS. What could cause such a change in preferences?

Both, Newhouse' argument and his evidence are related to the level of economic development. To find a mechanism by which wealth leads to changes in preferences towards "immaterial" things which do not contribute to what is the "actual task" of the HCS, one can resort to changes in values and motives of the citizens in the political domain. There is an observation concerning a change in the political domain from materialist to post-materialist values, initiated by Inglehart (1972), which in turn rests on Maslow's hierarchy of needs: if people get richer, the material questions of survival and physical wellbeing are basically settled. People take these achievements for granted. Now they want other things in addition, for instance political influence or selfactualization, see Maslow (1954). Radical political protest, like the one in the 1968s, can be explained by a change of preferences. The political systems in the Western world were still able to produce material wealth and security, but in particular for the younger generations, for which these outputs were "standard", this was no longer enough. They demanded different things, not as a replacement, but as an addition on top of the things the political systems produced already.

Applied to health care this argument would predict that once the "basics" of health care are given, people indeed take them for granted - just as they take personal survival or political stability for granted. They develop a focus on beyondhealth output and things like HCS responsiveness as the equivalent of 'post-materialist preferences'. Equivalent to the argument of Inglehart, this development occurs parallel to the overall economic development, implying that the change is the more pronounced at higher the levels of economic development. And, further, the argument does not imply that restoring health is no longer required. Research on citizens' satisfaction with the political system in general and the government in particular indicates that "basic" outcomes like economic growth are of high importance, cf. Newton (2006). But just as with the question of physical wellbeing in the political arena, it implies that restoring health is not enough. Political self actualization, expressed in more direct forms of political participation has its equivalent in the health domain, where self actualization comes in the form of a more participatory and active role in the medical decision making.

This framework will be used to interpret the determinants of citizens' satisfaction with their HCS by combining individual level data on satisfaction, income and health related attitudes with properties and output of the HCS as predictors. The empirical test consists of an inference from what is delivered by the HCS, in particular delivered in terms of health and beyond-health outputs, and the level of satisfaction citizens have, on what is most important for satisfaction: 
If the level of health output is most important for the citizens' satisfaction, people still primarily expect the production of health.

If the production of health output is irrelevant for the citizens' satisfaction, respectively the level of beyond-health output is more important this implies that citizens take the 'curing' function for granted and expect more.

Further, it will be tested, whether the importance of determinants of satisfaction are conditional on individual and societal wealth. Following the argument made above, the hypothesis about the conditionality is that the higher the level of income or GDP, the more preferences have changed toward beyond-health outputs. The role of the HCS' production of beyond-health outputs for individual level satisfaction should be the stronger, the richer the society and the richer the individual.

\section{INDICATORS, DATA, AND METHOD}

The logic underlying the empirical implementation of the above argument is the following: Citizens in a country are confronted with a HCS which produces certain outputs, respectively a certain mix of health- and beyond-health outputs. It does so at certain costs, also produces its outputs with a certain efficiency (defined in terms of its input-output ratio, which might be good (much output at little input) or poor (little output while consuming much input). The above argument makes a statement about the importance of each of these factors - in particular each type of output. Both the costs and the efficiency of the HCS are of no interest but primarily serve as control variables. The question is, which output is - ceteris paribus - more important for satisfaction.

In order to capture, which health system output is most important, one needs indicators of two different types of outputs. Because the output is a property of the HCS, this data is macro-level data, which describes the HCS. For instance, the average number of life years lost which could be saved if the HCS works properly is a property of the HCS. The HCS, as it is installed in the country, is able to avoid the loss of a certain number of life years. The indicators of each output will be described in the following section.

At the same time, there are several factors at the individual level, which are potentially important for the individual's satisfaction the with the HCS. This data is genuinely microlevel data, such as attitudes.

Technically, an empirical analysis should strive to avoid an ecological fallacy, in the sense that there is a relationship at the macro-level, which cannot be supported at the microlevel, and vice versa, cf. the paragraph on the method below.

The analysis of the factors for citizens' satisfaction uses individual level survey data from an Eurobarometer survey and is restricted to the EU15 member states. The evidence of a change in the preferences for types of health system outputs during a society's economic development would be stronger if data for developing and industrialized states were available. Because the level of economic development does not differ largely in the sample, the change may be not pronounced.

The individual-level data is from the Eurobarometer 44.3 on 'Health Care Issues and Public Security', conducted dur- ing spring 1996. I have chosen this survey rather than Eurobarometer 49 or the more recent European Social Survey, since it contains not only the citizen's evaluation of the national HCS but also questions on health related attitudes and behavior which were not asked in other surveys. The WHO data on the beyond-health outputs and several control variables is compiled for the year 1997, and thus no survey which was conducted years later can be used. The raw data set consists of 16.235 cases in the then 15 EU member states.

\section{Dependent Variable}

The dependent variable is the individual's satisfaction with the state of the HCS as it is currently operating in the country. The variable Satisfaction is a 5-point scale ranging from 1, 'very dissatisfied', to 5, 'very satisfied'. An individual's satisfaction is of course also determined by personal experiences, and also subject to short term fluctuation. But there will be a systematic component, and the explanatory variables used later on will contribute to explain the systematic variation in this variable. As with all other quantitative approaches to attitude research, the most basic assumption is, that the HCS matters at least to some degree for the individual's satisfaction.

\section{Explanatory and Control Variables at the Macro-Level}

The macro-level data is 'objective' evaluative data on the HCS. The data concerns in particular the two types of outputs, health and beyond-health, but also other properties of the HCS which are potentially relevant for satisfaction and thus need to be controlled for. The macro-level data is compiled from the WHO's 2000 World Health Report, WHR, supplemented by data from the OECD Health Database; OECD (2005).

\section{Responsiveness}

There are several conceptualizations of beyond-health outputs; see in particular Mooney (1998). However, these highly elaborate lists of specific indicators have been operationalized and measured only for very few countries. The present study requires a proxy of beyond-health output, which is defined, operationalized and measured in a consistent way for a larger set of countries. The only available proxy fulfilling these criteria is the WHO's responsiveness index; see WHO (2000, pp147). This indicator, as defined by the WHO, is explicitly complementary to health output. Responsiveness, as defined by the WHO, captures the degree to which a HCS provides elements like patient autonomy, prompt attention, access to societal support networks for patients but also explicitly 'client orientation' and the quality of the amenities during medical treatments. High values indicate a responsive HCS. The responsiveness indicator is a weighted composite index, encompassing seven dimensions. Each dimension is in turn covered by several questionnaireitems, which where evaluated based on a survey of country experts; see Annex 6 in WHO (2000) and Valentine et al. (2000) for a detailed description of the survey and the construction of the responsiveness index. Despite some critique, given for instance by Williams (2001), Navarro (2001) and Richardson et al. (2003), the WHO responsiveness index is the only available proxy of beyond-health output, which can reasonably claim to be a valid, albeit imperfect measure. Moreover, most of the critique raised concerns the quality of 
the survey data on which the evaluation is based. The argument is that for developing countries, the information on which the evaluation is based, such as amenabilities and respect for the patient, is difficult to obtain in a valid way - in particular for outsiders and foreign experts. This issue can be assumed to be much less of a problem for the industrialized countries in the sample. Here, there are enough experts to conduct a valid survey on the domestic health system's achievement regarding the defined lists of elements of responsiveness.

\section{With Regard to Health Output, Three Indicators are Used}

\section{Life Expectancy}

Is the life expectancy of both sexes for the year 1996, from the OECD Health Data, is a first indicator for the health output. The measure is not quality or disability adjusted, but contrary to other, more valid indicators, it is a figure which is highly present in the public discourse and the media. Thus, one might presume that if citizens think about the performance of their health system, they have this figure in mind.

\section{Mortality Amenable to Health Care}

It is empirically difficult to isolate the contribution of the HCS to the health status. Health status is influenced by a wide range of other factors, like income, education, lifestyles and environmental conditions; see Berger \& Messer (2002), Meer et al. (2003) and Nolte \& McKee (2003). Using crude life expectancy as an indicator of a HCS' curingperformance is hence problematic. An alternative indicator is the concept of mortality amenable to health care; see Nolte $\&$ McKee (2003). This indicator captures, how much mortality is due to conditions, which could be treated given the current state of medical knowledge. High values or the variable imply that many people suffer or even die of conditions which are treatable but aren't treated. Thus, high values indicate that the HCS fails in producing health output. Calculating such measures requires detailed medical knowledge and data on mortality. The data used here is from Nolte \& McKee (2003), who calculated the figures using very detailed statistics on mortality. It is measured as standardized death rate per 100.000 inhabitants for 1998. The variable does not cover Belgium and Luxembourg.

\section{Life Years Lost}

This variable is an alternative proxy indicator for health output, capturing how much of the mortality that could be avoided by the HCS is actually avoided. The idea is very much along the lines of the "Mortality amenable to health care". I constructed a "life years lost" indicator, using the difference between all life years lost and life years lost due to external causes, such as suicide and accidents using the OECD Health Data for 1996. As it is, the OECD's life years lost figure presumes that people in an OECD country should live till at least 75 , and all years of life lost by people dying below that age are avoidable - either by the HCS or by other forms of interventions. While this proxy is not as sophisticated as the indicator by Nolte and McKee, it can be constructed for all 15 countries in the sample.

A citizen's satisfaction with the HCS might be influenced by other macro-level factors and properties of the HCS. For instance, the HCS might work well, but the distribution of the financial burden of financing the HCS might be considered unfair by the citizens. To cover the potential impact of such factors, the following macro-level control variables are included:

\section{GDP}

Regarding the argument, that the importance of a HCS output on individual satisfaction is conditional on the level of economic development, the GDP was used as an control variable. GDP is the 1996 GDP per head in 1000 PPP Dollars from the OECD Health Data.

\section{Efficiency}

Satisfaction might depend on the productive efficiency of the HCS. In health care just as in other "enterprises", productive efficiency is defined by the question whether the HCS is turning the financial input into the maximum of output. Or, are resources consumed by the HCS itself, e.g. for its internal operation, without yielding a corresponding output of any type? Citizens might be satisfied with what the HCS delivers, but be nevertheless dissatisfied because the HCS wastes resources to do so. A case in point is if citizens perceive the HCS administration as being to big and too costly. The efficiency indicator used is not about what output levels are reached, but is defined as the degree to which resource input is actually transformed into health- respectively beyond-health outputs, asking, whether the HCS is reaching the output levels which could be reached with this input. The health-output level is corrected for the effects of education and economic development. High values indicate productive efficiency. The version of the indicators chosen uses the overall attainment, a composite measure combining healthand beyond-health output (mostly DALE production, but supplemented by the level of responsiveness) for the year 1997; see Evans et al. (2000) and Annex 10 in WHO (2000) for a documentation. The data is taken from Annex (Table 10 ) in WHO (2000). There is also a second indicator, which only uses the production of health outputs as a criterion. In the statistical analysis, the results do not differ.

\section{Fairness}

Citizens might be satisfied with the way the HCS works and what it produces, but be highly dissatisfied with the way it is financed, which might be considered unfair. To avoid a potential bias, I have included the WHO's index of fairness as a control variable. The index measures, whether the financial burden of health care financing is distributed in a fair way across all households in the nation. A value of 1 indicates fairness in the sense that all households contribute a similar share of their "above subsistence level income" to the HCS. The data is for 1997; see WHO (2000; Annex 7 and Table 7).

\section{Out of Pocket}

A similar argument concerns out of pocket payments by citizens. Citizens might be dissatisfied with the HCS, because in their opinion too much has to be paid directly by the individual requiring medical services, which puts a higher burden on people who are ill. The indicator is the average out of pocket payment per capita in international dollars for 1997; see Annex Table 8 in WHO (2000). 


\section{HCE}

Expenditure for health, HCE, is a very "visible" figure, which is often reported in the media and often compared among countries. Citizens, seeing only this figure in absolute terms, might become dissatisfied with the HCS, feeling that it requires too much resources. The indicator is the total HCE per head in PPP Dollars, for the year 1996, from OECD Health Data.

\section{Physicians}

In particular the beyond-health outputs require much time and hence much medical staff. For instance, if the GP is explaining the patient the medical problem, the options, and the risks, in order to enable the patient to contribute in the decision making process, this requires time. If there is a shortage of staff, the staff might not be able to spare the time required for being responsive in the way described here as an example. A relatively low level of physicians per capita, indicates a relative shortage of medical staff, in particular compared to the other countries in the sample. This might lower the satisfaction in the sense that there is not enough personnel to deliver beyond-health outputs. The indicator used is the number of practicing physicians per 1000 inhabitants in 1996 taken from the OECD Health Data.

These macro-level variables were attached to the dataset on the country basis, for instance all French respondents have the same values for GDP, life expectancy etc.

\section{Explanatory and Control Variables at the Micro-Level}

The attitude towards the HCS is also influenced by personal features of the individual. Micro-level control variables which are potentially relevant are socioeconomic factors, e.g. age, sex, education and income, but also variables concerning attitudes related to health and health care. Independent from the properties of the HCS, an individual might have attitudes and properties, which affect satisfaction with the HCS in a systematic way.

\section{Essentials}

This questionnaire item captures the respondent's agreement to the statement that the government should only provide essential medical services, measured from 'disagree strongly' (1) to 'agree strongly' (5). Of all attitudes, this one is closest to a preference for beyond-health outputs. People who are expecting more than 'curing' should reject such governmental restrictions on services which would limit what the HCS produces to health-outputs only.

\section{More Time}

This variable is the respondent's agreement to the statement that 'doctors do not spend enough time discussion preventive action and healthy lifestyle with their patients'. This content encompasses two aspects: whether physicians spend enough time with their patients and whether physicians care enough about prevention. Both issues are not about the curing of an existing illness. As such they are interpreted as an indicator of an individual's preference for health related information and thus as a beyond-health output.

\section{Prevention}

This variable is an additive index capturing the respondent's participation in preventive medical checkups. The more preventive checkups the respondent participated in, the higher the score and the higher the health awareness of the patient.

\section{Education}

The number of years of education absolved at the time of the survey was used as a measure of the respondent's educational achievement.

\section{Income}

The income variable is recoded into four quartiles, with 1 for the lowest and 4 for the highest income quartile. The problem of selection bias for the income variable, as described by King et al. (2001) is recognized. Because the income variable is central for the argument, it will be used despite the problems.

Given the argument that the preference for "caring" and beyond-health outputs is conditional on wealth, the effect of responsiveness should be conditional on the individual's or the society's wealth. This conditionality is controlled for by including two multiplicative interaction variables between responsiveness and income, Income* Responsiveness, respectively responsiveness and GDP, GDP*Responsiveness. If these variables have significant effects on satisfaction, responsiveness as an output of the HCS is more important for wealthier persons or in wealthier countries.

\section{Method: Multilevel Regression}

Macro-level analyses of the determinants of satisfaction, HCE and various measures of HCS performance, show that at the percentage of people very or fairly satisfied with the $\mathrm{HCS}$, is much more dependent on the responsiveness than on the HCS' performance in restoring health; see e.g. Mossialos (1997), and Blendon et al. (2001). These analyses are problematic, if one wants to make statements on the role of health system features and individual level features on an individual's satisfaction with the HCS. Macro-and individual level relationships might differ, and it is possible to succumb to an ecological fallacy of a purely artificial relationship.

The nature of the available data raises two problems, which make the usage of a conventional OLS regression problematic. First, the data consists of individual cases nested within HCS. The empirical analysis uses characteristics of individuals but also of the HCS, which are the same for all individuals from that HCS. One has explanatory factors originating from two levels: features of the HCS, and features of the individual. Using standard OLS implies treating features of the HCS as a property of an individual. This is conceptually inappropriate and at the technical level leads to overestimated significance levels for macro-level variables. The appropriate method is hence a multilevel regression; see Snijders \& Bosker (1999) and Steenbergen \& Jones (2002). Second, the dependent variable is a 5-point scale, borderline between metric and ordinal measurement level. I have decided against an ordinal logit model for several reasons. First, to capture the multilevel structure of the data, to obtain information on the explanatory power of macro-level factors - here the features of the HCS - as opposed to microlevel features - the properties of the individuals - the statistical implementations of linear models are more developed. Multilevel routines are available for binary logit models, which would imply a more or less arbitrary recoding of the 
dependent variable into a dichotomous satisfied / dissatisfied variable, with a substantial loss of information. Second, the obtained $\mathrm{R}^{2}$, which in the case of a multilevel regression indicate the explanatory contribution of the macro- respectively the micro-level variables, are easier to interpret in terms of variation occurring between HCS and within a HCS. Moreover, the obtained coefficients are easier to interpret, without having to calculate the marginal effects on probabilities for all five categories of the dependent variable. Third, the dependent variable has five categories, and in this case, using a linear regression does not lead to biased results; see Bollen (1989, pp 433). It shall be remarked that if one ignores the multilevel structure of the data, the coefficients and the basic findings obtained from an ordinal logit model are very similar to those obtained from the OLS regression which was implemented here, indicating that there is no bias arising from the categorization of satisfaction into five categories. As a last point to consider, the multilevel data structure restricts the number of macro-level variables includable in the analysis. Despite about 10.000 individual cases remaining after missing values were excluded, there are only fifteen cases at macro-level. As a consequence, inference on the significance of the macro-level variables is based on fifteen cases only. Hence the analysis was constrained to a basic model containing the macro-level variables most interesting from the theoretical point of view. Responsiveness as an indicator for the "caring" function. In turn, this output was supplemented by one of the three indicators of the "curing" function and one further macro-level control variable respectively an interaction variable. The micro-level variables are not subject to these restrictions, and were included en bloc. The implementation was done using STATA's xtreg routine. An alternative routine, GLLAMM, using the ordinal logit variant, confirms the coefficients. Unfortunately, GLLAMM does not yield the shares of variation explained by the macro- and micro-level variables. This information is relevant to see whether the effects of the HCS properties matter at all.

\section{RESULTS}

Table 1 gives the macro- and micro-level determinants of satisfaction of individuals with their HCS ('satisfaction'), comparing the relevance of health and beyond-health output levels.

Regarding the main question, the central result is that responsiveness, the beyond-health-output, is the most important macro-level determinant of an individual's satisfaction, while the HCS' health output achievement is next to irrelevant. The finding is robust: modifications, e.g. different indicators of the 'curing' function and the inclusion of control variables, do not change this result.

Regarding the macro-level indicators of health output, the three columns in the left section of (Table 1) report the results of the basic model complemented by Life Expectancy; Life Years Lost, respectively the level of mortality amenable to health care ("Am.Mortality") as an indicator of the HCS' health output. Neither of these indicators of biological health output significantly matters for citizen's satisfaction with the HCS.

The micro-level variables have stable coefficients throughout all model variations, indicating that they repre- sent an explanatory contribution, which is independent from the macro-level variables. Of the socioeconomic factors only age has a significant, albeit very small impact on satisfaction. Sex, education and income have no significant coefficients. Personal attitudes, in particular from the domain of health care, are much more relevant. Two attitudinal variables, which can be interpreted as indicators for an individual's preferences, are significant for satisfaction. The variable 'Essentials' directly captures a person's opinion about whether the government should restrict the bundle of services offered by the HCS to what is "essential", i.e. necessary medical services and health output. People who are expecting only the essential function of health production from a HCS, are significantly more satisfied with the HCS than people holding the contrary opinion that the HCS should deliver more than just the "essentials". The higher level of satisfaction among persons who are primarily expecting health outputs is little surprising, because of the high level of achievement in health production by the HCS in the sample. People who are expecting the physician to spend more time with them are significantly less satisfied with their HCS. Since the questionnaire item concerns a type of activity (explaining preventive measures), which is not directly related to curing an illness, the individual's agreement with the statement indicates that this respondent expects more than the curing of incurred illnesses from the personnel working in the HCS. The general health awareness of the respondent, measured by the participation in preventive medical checkups, has an - albeit weak and borderline significant - diminishing impact on satisfaction.

Including macro-level control variables does not change the central results of the analysis. The middle section of (Table 1) reports the results of the basic model, using responsiveness and Life Expectancy as indicator of the two outputs. The two outputs were in turn supplemented by one macro-level control variable: by the health system's "Efficiency", the level of "HCE", the number of "Physicians", the level of "Out of Pocket" payments and the "Fairness" of the financial contributions to the HCS. The control variables differ regarding to the degree to which citizens are directly confronted with them. "Efficiency" is a highly abstract concept, of which citizens might be not aware. On the other hand, out of pocket payments are something citizens are well aware of because they themselves are subjected to feature. Just as before, responsiveness as the indicator of beyondhealth output remains a strong determinant of individuallevel satisfaction, while the indicator of health output has basically no effect. Satisfaction, where it exists, is due to high levels of responsiveness, not due to things like fairness, efficiency or low levels of out-of-pocket payments.

With regard to the statistical significance, the inclusion of a fourth macro-level variable diminishes the chances of significant coefficients due to the abovementioned problem of a small number of cases at the macro-level. None of the control variables has a significant effect.

Interestingly, the "objective" efficiency of the HCS, at least as measured by the WHO, decreases satisfaction. Health systems, which produce the maximum of health output for the resources they have available, do not per se satisfy the citizens. It is not the technical efficiency which matters, but the composition of the outputs. In terms of the 
Table 1. Determinants of Individual Satisfaction with the HCS

\begin{tabular}{|c|c|c|c|c|c|c|c|c|c|c|c|}
\hline & \multicolumn{3}{|c|}{ Indicators of Curing } & \multicolumn{5}{|c|}{ Macro-Level Control Variables } & & \multicolumn{2}{|c|}{ Interaction Models } \\
\hline & $\begin{array}{c}\text { Life } \\
\text { Expectancy }\end{array}$ & $\begin{array}{c}\text { Life Years } \\
\text { Lost }\end{array}$ & Am Mortality ${ }^{1)}$ & Efficiency & $\mathrm{HCE}$ & $\begin{array}{c}\text { Physicia } \\
\text { ns }\end{array}$ & OoPocket $^{2)}$ & Fairness & & $\begin{array}{c}\text { Income } \\
\text { Responsive } \\
\text { ness }\end{array}$ & $\begin{array}{c}\text { GDP } \\
\text { Responsive- } \\
\text { ness }\end{array}$ \\
\hline \multicolumn{12}{|c|}{ Macro-Level Variables } \\
\hline \multirow[t]{2}{*}{ Responsiveness } & 2,003 & 1,980 & 1,963 & 1,511 & 2,476 & 2,243 & 2,135 & 1,459 & & 2,033 & 2,305 \\
\hline & 2,630 & 2,390 & 1,250 & 1,560 & 1,900 & 3,270 & 2,000 & 2,240 & & 3,570 & 2,480 \\
\hline \multirow[t]{2}{*}{ GDP (in 1000\$) } & $-0,075$ & $-0,074$ & $-0,064$ & $-0,041$ & $-0,086$ & $-0,104$ & $-0,091$ & $-0,075$ & & 0,000 & 0,111 \\
\hline & $-1,150$ & $-1,080$ & $-0,380$ & $-0,540$ & $-1,100$ & $-1,720$ & $-1,000$ & $-1,460$ & & $-1,540$ & 0,270 \\
\hline \multirow[t]{2}{*}{ Control Variable } & & & & $-0,019$ & $-0,060$ & $-0,019$ & $-0,032$ & $-0,077$ & & $-0,077$ & $-0,094$ \\
\hline & & & & $-0,140$ & $-0,430$ & $-0,180$ & $-0,180$ & $-0,850$ & & $-0,900$ & $-0,910$ \\
\hline $\begin{array}{c}\text { Curing } \\
\text { Indicator }^{3)}\end{array}$ & $-0,078$ & 0,000 & 0,003 & $-3,901$ & 0,000 & $-0,273$ & $-0,001$ & 35,457 & I-term $^{4)}$ & $-0,012$ & $-0,025$ \\
\hline \multicolumn{12}{|c|}{ Micro-Level Variables } \\
\hline \multirow[t]{2}{*}{ Female } & $-0,005$ & $-0,005$ & $-0,006$ & $-0,005$ & $-0,005$ & $-0,005$ & $-0,004$ & $-0,005$ & & $-0,005$ & $-0,005$ \\
\hline & $-0,260$ & $-0,260$ & $-0,300$ & $-0,260$ & $-0,260$ & $-0,260$ & $-0,240$ & $-0,260$ & & $-0,270$ & $-0,260$ \\
\hline \multirow[t]{2}{*}{ Age } & 0,002 & 0,002 & 0,002 & 0,002 & 0,002 & 0,002 & 0,002 & 0,002 & & 0,002 & 0,002 \\
\hline & 2,910 & 2,910 & 3,080 & 2,900 & 2,900 & 2,900 & 2,910 & 2,900 & & 2,940 & 2,910 \\
\hline \multirow[t]{2}{*}{ Education } & 0,001 & 0,001 & 0,002 & 0,001 & 0,001 & 0,001 & 0,000 & 0,001 & & 0,001 & 0,001 \\
\hline & 0,420 & 0,410 & 0,700 & 0,410 & 0,410 & 0,430 & 0,140 & 0,420 & & 0,390 & 0,430 \\
\hline \multirow[t]{2}{*}{ Income } & 0,010 & 0,010 & 0,013 & 0,010 & 0,010 & 0,010 & 0,008 & 0,010 & & 0,089 & 0,010 \\
\hline & 1,190 & 1,200 & 1,480 & 1,200 & 1,200 & 1,190 & 0,900 & 1,190 & & 0,580 & 1,190 \\
\hline \multirow[t]{2}{*}{ Essentials } & 0,053 & 0,053 & 0,054 & 0,053 & 0,053 & 0,053 & 0,053 & 0,053 & & 0,053 & 0,053 \\
\hline & 7,500 & 7,500 & 7,240 & 7,500 & 7,500 & 7,510 & 7,400 & 7,510 & & 7,490 & 7,500 \\
\hline \multirow[t]{2}{*}{ Prevention } & $-0,007$ & $-0,007$ & $-0,008$ & $-0,007$ & $-0,007$ & $-0,007$ & $-0,006$ & $-0,007$ & & $-0,007$ & $-0,007$ \\
\hline & $-1,940$ & $-1,940$ & $-1,970$ & $-1,940$ & $-1,930$ & $-1,930$ & $-1,590$ & $-1,930$ & & $-1,950$ & $-1,940$ \\
\hline \multirow[t]{2}{*}{ MoreTime } & $-0,122$ & $-0,122$ & $-0,121$ & $-0,122$ & $-0,122$ & $-0,122$ & $-0,121$ & $-0,122$ & & $-0,122$ & $-0,122$ \\
\hline & $-15,860$ & $-15,860$ & $-15,080$ & $-15,850$ & $-15,860$ & $-15,850$ & $-15,630$ & $-15,860$ & & $-15,860$ & $-15,860$ \\
\hline \multirow[t]{2}{*}{ Constant } & $-2,258$ & $-8,039$ & $-8,491$ & $-0,571$ & $-5,890$ & $-6,945$ & $-5,991$ & $-33,191$ & & $-2,490$ & $-3,365$ \\
\hline & $-0,230$ & $-1,710$ & $-1,090$ & $-0,060$ & $-0,440$ & $-0,760$ & $-0,400$ & $-2,000$ & & $-0,350$ & $-0,400$ \\
\hline Within $\mathrm{R}^{2}$ & 0,028 & 0,028 & 0,028 & 0,028 & 0,028 & 0,028 & 0,028 & 0,028 & & 0,028 & 0,028 \\
\hline Between $\mathrm{R}^{2}$ & 0,725 & 0,707 & 0,698 & 0,752 & 0.738 & 0.781 & 0.786 & 0.832 & & 0,725 & 0,731 \\
\hline Overall $\mathrm{R}^{2}$ & 0,211 & 0,207 & 0,210 & 0,221 & 0,221 & 0,225 & 0,229 & 0,238 & & 0,211 & 0,214 \\
\hline Sigma u & 0,46 & 0,48 & 0,68 & 0,46 & 0,53 & 0,40 & 0,64 & 0,36 & & 0,34 & 0,39 \\
\hline
\end{tabular}


Table 1. Contd....

\begin{tabular}{|c|c|c|c|c|c|c|c|c|c|c|}
\hline \multirow[b]{2}{*}{ Sigma e } & \multicolumn{3}{|c|}{ Indicators of Curing } & \multicolumn{5}{|c|}{ Macro-Level Control Variables } & \multicolumn{2}{|c|}{ Interaction Models } \\
\hline & 0,96 & 0,96 & 0,97 & 0,97 & 0,97 & 0,97 & 0,95 & 0,97 & 0,97 & 0,97 \\
\hline \multicolumn{11}{|l|}{ Remarks: } \\
\hline \multicolumn{11}{|c|}{ Values reported are b-coefficients and z-values } \\
\hline \multicolumn{11}{|c|}{ Headline label denotes the control/interaction variable } \\
\hline \multicolumn{11}{|c|}{$\begin{array}{l}\text { 4) Interaction term is denoted in the column's headline } \\
\text { control variable is GDP }\end{array}$} \\
\hline
\end{tabular}

framework underlying the analysis, the negative effect of technical efficiency on satisfaction reflects that the efficient production of health outputs implies to some degree a renouncement of responsiveness. If the HCS' raison d'être consists of producing health as efficiently as possible, involving the patient, by enabling her to have a role in the decision making process, is a waste of resources, because these efforts do not contribute to the health status, and may even be an obstacle. While the efficiency measurement by the WHO to some degree also takes into account the responsiveness level achieved, the assumption underlying the WHO's efficiency indicator is that the HCS should primarily produce as much biological health as possible with the financial input used. This view necessarily implies that devoting resources to responsiveness lowers efficiency, because less health is produced than what would be possible given the level of financial input.

While issues as efficiency and fairness dominate the public discussion, citizen's satisfaction seems to be quite independent from the standard indicators of HCS performance and the standard issues of health policy, like expenditure levels, fairness and out of pocket payments.

Analyzing variation using a multilevel regression distinguishes two components. An individual's deviation from the sample's "grand mean" is composed of the deviation of the county's mean from the grand mean, and the deviation of an individual from the country mean; cf. Snijders \& Bosker (1999: 16-22). Macro-level variables explain a country's deviation from the grand mean, i.e. the variation of the average satisfaction between countries (between- $\mathrm{R}^{2}$ ). Individuallevel variables, such as attitudes, explain the variation in the satisfaction among individuals within a country (within- $\mathrm{R}^{2}$ ). Looking at the explanatory power, one finds that all model variants explain about $20 \%$ of the overall variation in satisfaction. The micro-level variation is much less amenable to an explanation. The within-country $\mathrm{R}^{2}$ of only about $3 \%$ is an indication that many other factors are relevant for an indi- vidual's satisfaction, presumable personal experiences with the HCS. The macro-level variables explain to a very high degree the differences between the countries. The betweencountry $\mathrm{R}^{2}$ is $70 \%$ or higher, and varies depending on the macro-variables chosen. The outputs and the features of the HCS used explain quite well why citizens in country A have on average higher levels of satisfaction than citizens in country B. To summarize, there is a systematic component in satisfaction, due to the properties of the country and also the country's HCS, but there is also a substantial component which is due to the subjective experiences an individual gathers with the HCS.

How about the conditionality of the role of factors on wealth? First, there is no significant effect of either societal or personal wealth (proxied by GDP and income) on satisfaction. Richer people and people in richer societies are not per se less satisfied. If they were, this would indicate higher expectations for richer people, which are not met by the HCS in its current form. This finding can be interpreted that the HCS adapts to the citizen's preferences. The observation that the levels of responsiveness are usually substantially lower in the less wealthy countries in the sample supports this interpretation.

The conditionality-hypothesis stated that the importance of the HCS' responsiveness for individual level satisfaction is higher in richer societies and for richer individuals. In technical terms this to say that the coefficient of responsiveness is bigger in wealthier countries and for wealthier persons. In order to test the hypothesis two multiplicative interaction effects, GDP*Responsiveness and Income*Responsiveness, were included. The results obtained are reported in the two rightmost columns of (Table 1). The basic model contains the two outputs, and GDP as a control variable. This model is supplemented by the interaction term GDP*Responsiveness respectively Income*Responsiveness. The prediction based on the hypothesis would be that both interaction terms have strong positive coefficients: the 
wealthier an individual or a society, the more relevant is the HCS' responsiveness for satisfaction. However, both interaction effects remain insignificant without changing the main finding. So, contrary to the hypothesis, a HCS' responsiveness is not more relevant for satisfaction in richer societies or for richer persons.

\section{SUMMARY AND POLICY IMPLICATIONS}

The aim of the paper was to identify what citizens factually expect from their health system by analyzing the role of health system outputs, HCS features such as fairness and efficiency, and individual level properties on an individual's satisfaction with the HCS. Having elaborated the beyondhealth vs. health output distinction and why one can expect the former output to be more important in societies with higher levels of development, the central empirical question was, Are citizens satisfied with a HCS which is "only" producing health output? Or do citizens take the fact that a HCS delivers what is "necessary", for granted and want other things in addition, such as beyond-health-output? Can health policy makers hope to obtain and retain support for a HCS, which is designed for effectively and efficiently producing health, but nothing else?

The argument to be tested was that citizens' expectations have changed and that in developed, industrialized countries, the mere production of "health output" is no longer sufficient to satisfy the citizens.

The empirical evidence indicates that individuals from industrialized countries do indeed no longer evaluate the HCS on the basis of its health output. Health output, the fact that the HCS is able to cure illnesses, is of course relevant, but this relevance remains implicit, because the HCS' ability to cure illnesses is taken for granted. Explicit satisfaction is not achieved by doing only what is "necessary" or "essential". It goes without saying that if the HCS would underperform or be unable to produce health outputs for whatever reason, satisfaction would drop. But as it is, in particular given the high level of achievement in health production, this output is no longer the criterion by which the HCS is evaluated. This finding is not an artifact due to using an inappropriate indicator of health output. Several indicators of health output were used, in particular to control for the problem that health is also produced outside of the HCS, in the sense that the overall living conditions prevent that people fall ill in the first place. All health output indicators, even those which directly measure the contribution of the HCS to the health status in the sense of actually achieving "curing", are equally irrelevant for satisfaction.

Instead responsiveness, a beyond-health output which covers the procedural aspect of health production, is the major determinant of individual satisfaction. Citizens not only expect to be cured, but to be cured in a way which pays respect to them as a person, gives them a role in the decision making process and also offers certain standards regarding aspects like accommodation standards in the hospitals. Citizens evaluate the HCS primarily with respect to an output, which is 'unnecessary' for the restoration of biological health, but which is something rather immaterial, produced in addition to what the HCS was originally installed to produce.
With regard to the reason for this change in citizens' preferences and expectations, the available evidence is weaker. There is, contrary to what was derived from the explanatory mechanism proposed, no significant conditionality in the determinants of an individual's satisfaction. Neither are persons in wealthier societies systemically less satisfied with the HCS, nor are wealthier persons generally less satisfied. In particular there is no interaction among wealth and the importance of responsiveness: Responsiveness does not matter more for wealthier people nor matters more in wealthier societies.

The available sample of countries is determined by the fact that sufficient information about all outputs and features of the HCS is only available for some countries. Countries, which are quite wealthy and developed in economic terms. Because of this restriction, one can suppose that the absence of the conditionality is due to the fact that the sample consists of comparatively wealthy countries. In particular, there are no developing countries in the sample, because for them no survey data on satisfaction with HCS is available. One could thus argue, that the change in citizens' preferences occurred at lower levels of wealth, i.e. earlier in economic development. As all countries in the sample underwent this change earlier on, they do not differ in this regard. The evidence of a change in the preferences concerning the two outputs care during a societies' economic development might be stronger if very different levels of wealth were covered by the sample. Ideally, one would use information on developing as well as developed countries. The lack of survey data on satisfaction from developing countries precluded this option.

The empirical analysis controlled for a range of potential control variables, such as fairness and efficiency. The argument is that they might influence satisfaction but also that they dominate the public discourse on health policy. None of them affects the basic finding. Interestingly, the "objective" evaluative criteria on which much of the public debate in health policy is focused, like fairness or efficiency, are equally irrelevant for satisfaction. Increasing health system efficiency, producing more health in exchange for the money devoted to health or produce the same quantity of health with less money, is among the predominant aims in health policy. But given the evidence, achieving this aim will not make citizens more satisfied.

What are the policy implications of these findings? While this paper does not purport that health expenditure is increasing only due to the production of "caring" and beyond-health output, cf. Cutler et al. (1996) as an example of the many inquiries into the sources of expenditure growth, it acknowledges the existence of this output and the consequences. There are several implications, ranging from the perception of what the task of a HCS is, to the issue of what one obtains in exchange for all the money which goes into the HCS.

Policy makers in the health domain and also citizen tend to agree that the health system is "too expensive". At the same time, the latter demand more of an output, which is not available for free. Yet citizens and policy makers seemingly assume that the "responsiveness" which they value so highly, is somehow provided for free and as a matter of course. But this perception is wrong. If health policy makers want to satisfy the demands and expectations of their voters, 
the existence and the production of responsiveness should be explicitly taken into account.

The HCS can produce the two different outputs, but to do this, to produce for instance responsiveness, it must be at the institutional level designed to allow for the production of this output. If for instance the GP is remunerated in a way which precludes that she has the time required to be responsive, the HCS is institutionally unable to deliver this output; cf. Dusheiko et al. (2004). The institutional setting - here the remuneration mode - prohibits the production of this output. The same is true if the number of medical staff is reduces and the workload of each person providing care is increased. If the HCS is reformed at the institutional level - and there are many instances of such efficiency improvements with the explicit aim to obtain more health-output for the same input of money and manpower (i.e. of time which is available to be responsive to the patient) - this will systematically reduce the production of an output which is highly relevant for the citizens. Defining health system efficiency - the improvement of which is the target of so many health system reforms in recent times - as being only based on the ratio of financial input to health output falls short, because a crucial output is not or insufficiently included in the calculation. A seemingly inefficient health system may be producing an output, but the value of this output is not taken into account.

Acknowledging the constraints on the financing of health care and the perennial question of "What shall be paid for?", does not preclude the discussion of beyond-health output production. Instead, the discussion should be made explicit, and health policy makers should explicitly formulate the options: There are certain outputs, which require financial input, and the HCS can produce them or not - what is it, you, the electorate, want? If the production of the one output is reduced, the HCS may do with less financial resources. But then, there is nothing of this output. As it is, the debate indicates that health policy makers keep the trade-off implicit and thus contribute to a diffuse dissatisfaction, which is not addressed in all the efforts to reform and to improve the HCS because its reasons are left vague.

A similar discussion takes place when discussing which services shall be covered by the HCS and which services are to be covered by private funding. But the issue of responsiveness and beyond-health outputs is intertwined to a degree with the production of health, that one can not remove it from the system as one can remove a certain service or type of care, such as dental care. Nor can an output - such as involving citizens in the medical decision making process - be subjected to private funding or co-payments, as one can charge citizens for a single room in a hospital.

With regard to health policy the main implication is that the change in expectations about health care should be acknowledged. Interestingly, in the public and the political discourse, beyond-health output is often not addressed at all. Given its relevance, this output should be explicitly discussed and be included in the "value for money" calculation, on which the judgment that a certain HCS is "too expensive" is based. If the provision of beyond-health outputs is universally demanded, there is no reason why the HCS shouldn't deliver. To make the production of this output explicit would at least remove some of the observable inconsistencies in the debates on health systems, cf. Weisbrod (1991) and Oliver (2007).

\section{REFERENCES}

Aaron, H.J. (2003). Should public policy seek to control the growth of health-care spending? Health Affairs Web Exclusives, 10, w3-28w3-36.

Berger, M.C., \& Messer, J. (2002). Public financing of health expenditures, insurance, and health outcomes. Applied Economics, 34, 21052113.

Blendon, R.J., Kim, M., \& Benson, J.M. (2001). The public versus the World Health Organization on health system performance. Health Affairs, 20, 10-20.

Bollen, K.A. (1989). Structural equations with latent variables. New York: Wiley.

Cutler, D.M., Deaton, A.S., \& Lleras-Muney, A. (2006). The determinants of mortality. New York/Stanford: NBER Working Paper No. 11963.

Cutler, D.M., McClellan, M.B., \& Newhouse, J.P. (1998). What has increased medical-care spending bought? American Economic Review, 88, 132-136.

Donaldson, C., \& Shackley, P (1997). Does 'process utility' exist? A case study of willingness to pay for laparoscopic cholecystectomy. Social Science and Medicine, 44, 699-707.

Donelan, K., Blendon, R.J., Schoen, C., Davis, K., \& Binns, K. (1999). The cost of health system change: public discontent in five nations. Health Affairs, 18, 206-216.

Dusheiko, M., Gravelle, H., \& Yu, N. (2004). The impact of budgets for gatekeeping physicians on patient satisfaction: evidence from fundholding. York: Centre for Health Economics/ University of York CHE Technical Paper 30.

Evans, D.B., Tandon, A., Murray, C.J.L., \& Lauer, J.A. (2000). The comparative efficiency of national health systems in producing health: an analysis of 191 countries. Geneva: WHO: Global Programme on Evidence for Health Policy Discussion Paper Series: No. 29.

Freeman, D.G. (2003). Is health care a necessity or a luxury? Pooled estimates of income elasticity from US state level data. Applied Economics, 35, 495-502.

Grossman, M. (1972). On the concept of health capital and the demand for health. Journal of Political Economy, 80, 223-255.

Ham, C. (2005). Money can't buy you satisfaction. British Medical Journal, 330, 597-599.

Inglehart, R. (1977). The silent revolution: changing values and political styles among western publics. Princeton: Princeton University Press.

Jackson, J.L., Chamberlinc, J., \& Kroenked, K. (2001). Predictors of patient satisfaction. Social Science and Medicine, 52, 609-620.

King, G., Honaker, J.A., \& Scheve, K. (2001). Analyzing incomplete political science data: an alternative algorithm for multiple imputation. American Political Science Review, 95, 49-69.

Kohl, J. \& Wendt, C. (2004). Satisfaction with health care systems. A comparison of EU countries. In: W. Glatzer, S. Below, M Stoffregen (Eds.), Challenges for Quality of Life in the contemporary world. Advances in quality-of-life studies, theory and research, (pp. 311331). Dordrecht: Kluwer Academic Publishers.

Maslow, A.H. (1954). Motivation and personality. New York: Harper \& Row.

Meer, J., Miller, D.L., \& Rosen, H.S. (2003 ). Exploring the health-wealth nexus. Journal of Health Economics, 22, 713-730.

Mooney, G. (1998). Beyond health outcomes: the benefits of health care. Health Care Analysis, 6, 99-105.

Mossialos, E. (1997). Citizens' views on health care systems in the 15 member states of the European Union. Health Economics, 6, 109-116.

Mossialos, E., Dixon, A., Figueras, J., \& Kutzin, J. (Eds.). (2002). Funding health care: options for Europe. Buckingham/Philadelphia: Open University Press.

Navarro, V. (2001). The new conventional wisdom. An evaluation of the WHO report Health Systems: improving performance. International Journal of Health Services, 31, 23-33.

Newhouse, J.P. (1977). Medical-care expenditure: a cross-national survey. Journal of Human Resources, 12, 115-125.

Newton, K. (2006). Political support: Social capital, civil society and political and economic performance. Political Studies, 54, 846-864. 
Nolte, E., \& McKee, M. (2003). Measuring the health of nations: analysis of mortality amenable to health care. British Medical Journal, 327, 1129-1133.

Olsen, J.A., \& Smith, R.D. (2001). Theory versus practice: a review of 'willingness-to-pay' in health and health care. Health Economics, $10,39-52$.

Organization for Economic Cooperation of Development (2004a). Towards high-performing health systems. Paris: OECD.

Organization for Economic Cooperation of Development (2004b). Towards high-performing health systems: policy studies. Paris: OECD.

Organization for Economic Cooperation and Development. (2005) Health Data. Statistics and indicators for 30 countries. Paris: OECD.

Oliver, A. (2007). Inconsistent objectives - reflections on some selective health care policy developments in Europe. Health Economics Policy and Law, 2, 93-106.

Oliver, A., \& Mossialos, E. (Eds.) (2005). Legacies and latitude in European health policy. Durham: Duke University Press.

Richardson, J., Wildman, J., \& Robertson, I.K. (2003). A critique of the World Health Organisation's evaluation of health system performance. Health Economics, 12, 355-366.

Roberts, J. (1999). Sensitivity of elasticity estimates for OECD health care spending: analysis of a dynamic heterogeneous data field. Health Economics and Econometrics, 8, 459-472.
Saltman, R.B., \& Figueras, J. (1998). Analyzing the evidence on European health care reform. Health Affairs, 2, 85-108.

Saltman, R.B., Figueras, J., \& Sakellarides, C. (Eds.) (1998). Critical challenges for health care reform in Europe. Maidenhead/Philadelphia: Open University Press.

Sitzia, J., \& Wood, N. (1997). Patient satisfaction: A review of issues and concepts. Social Science and Medicine, 45, 1829-1843.

Snijders, T. A., \& Bosker, R.J. (1999). Multilevel analysis: an introduction to basic and advanced multilevel modeling. London: Sage.

Steenbergen, M.R., \& Jones, B.S. (2002). Modeling multilevel data structures. American Journal of Political Science, 46, 218-237.

Valentine, N.B., de Silva, A., \& Murray, C.J.L. (2000). Estimating responsiveness level and distribution for 191 countries: methods and results. Geneva: World Health Organization: Global Programme on Evidence for Health Policy Discussion Paper Series: No. 22.

Weisbrod, B.A. (1991). The health care quadrilemma: an essay on technological change, insurance, quality of care, and cost containment. Journal of Health Economics, 29, 523-552.

WHO (2000). The world health report 2000. Geneva: WHO.

Williams, A. (2001). Science or marketing at WHO? A commentary on 'World Health 2000'. Health Economics, 10, 93-100.

Received: December 02, 2008

Revised: April 16, 2009

Accepted: April 18, 2009

(C) Peter Kotzian; Licensee Bentham Open.

This is an open access article licensed under the terms of the Creative Commons Attribution Non-Commercial License (http://creativecommons.org/licenses/by-nc/3.0/) which permits unrestricted, non-commercial use, distribution and reproduction in any medium, provided the work is properly cited. 